\title{
Role of Temperature and Soil Moisture Conditions on Flavonoid Production and Biosynthesis-Related Genes in Ginkgo (Ginkgo biloba L.) Leaves Guibin Wang ${ }^{1}$, Fuliang Cao', Guangyu Wang² and Yousry A. El-Kassaby²*
}

${ }^{1}$ College of forest Resources and Environment, Nanjing Forestry University, Nanjing 210037, People's Republic of China

${ }^{2}$ Faculty of Forestry, University of British Columbia, Vancouver, BC, Canada

\begin{abstract}
The environmental factors affecting flavonoid biosynthesis and accumulation from Ginkgo (Ginkgo biloba L.) plants in production plantation settings is investigated to maximize their production.
\end{abstract}

Objectives: To develop an understanding of the environmental factors (temperature and available soil moisture and their inter-relationship) affecting flavonoids biosynthesis and accumulation in Ginkgo leaves for selection, development, and production purposes for commercial production.

Methods: A factorial experiment (temperature: $15 / 5,25 / 15$ and $35 / 25^{\circ} \mathrm{C}$ (day/night) and soil moisture: $55-60$, 40-45 and $30-35 \%$ of field capacity) using 2-year-old Ginkgo seedlings to estimated flavonoids content and their expression level in leaves sampled 10,20,30, 40 and 50days using high performance liquid chromatography and quantitative real-time PCR (qRT-PCR) of seven flavonoid biosynthesis-related genes, respectively.

Results: Flavonoid accumulation was significantly higher under lower temperature $\left(15 / 5^{\circ} \mathrm{C}\right)$ and available soil moisture (40-45 and $30-35 \%$ ) while it was severely suppressed under high temperature. qRT-PCR indicated that flavonoid biosynthesis differed greatly among the studied genes with some genes being up-regulated under lower or higher temperature and/or moisture.

Conclusion: Total flavonoid content was greatly affected by temperature and soil moisture content and their biosynthesis varied among the studied genes suggesting the presence of a synergistic effect on the expression of genes within the flavonoid biosynthesis pathway. The results contributed to the understanding of the environmental factors needed for the successful production of flavonoid from Ginkgo leaves harvest plantations.

Keywords: Ginkgo biloba; Flavonoid; Gene expression; Temperature; Soil moisture content

\section{Introduction}

Flavonoids are important secondary plant metabolites with many essential functions such as attractants and antioxidant enhancing pollination and seeds dispersal and plants' resistance to UV light, drought, cold temperature and wounding [1,2]. Flavonoids are also valuable human nutrition and health agents due to their multiple biological activities (e.g., anti-inflammatory, allergenic, bacterial, carcinogenic and viral) [3].

It has been clearly demonstrated that environmental factors, such as temperature, light, and soil moisture content, affect flavonoid biosynthesis and accumulation in many plants [4-7]. Additionally, several flavonoid biosynthesis pathway genes are expressed various parts of flowering plants (e.g., flowers, fruits, seeds, and leaves), with some have been isolated and characterized (e.g., grape [8]; azaleas $[9,10]$; bilberry [11,12]; Ginkgo [13]).

Ginkgo is a traditional commercial tree species in China and it is widely planted for leaves, flowers, fruits, and timber harvesting. The medicinal value of Ginkgo leaves prompted the establishment of large scale Ginkgo plantations for the sole purpose of leaf-harvesting for flavonoids and terpene lactones extraction $[14,15]$. While some studies have been conducted to determine the role of environmental factors on flavonoid biosynthesis and accumulation in Ginkgo leaves, present knowledge is still incomplete due to the complex and confounding nature of field testing that precluded isolating the role of each environmental effect individually [16,17]. Furthermore, it has not yet been clarified how the genes of flavonoid biosynthesis pathway respond to various combinations of temperature and soil moisture content.

The present study is conducted to clarify and investigate the inter-relationship between temperature and soil moisture content on flavonoid accumulation as well as the expression of flavonoid biosynthesis-related genes in Ginkgo (Ginkgo bilobaL.). Phytotrons were used to provide controlled environmental conditions using 2-year-old seedlings.

\section{Materials and Methods}

\section{Plant materials and experimental procedures}

A factorial experiment with two main factors (temperature and soil moisture content), each with three levels (temperature: $15 / 5^{\circ} \mathrm{C}$ (day/ night), $25 / 15^{\circ} \mathrm{C}$ and $35 / 25^{\circ} \mathrm{C}$ designated as $\mathrm{T} 1, \mathrm{~T} 2$ and $\mathrm{T} 3$, respectively, and soil moisture content: $55-60 \%, 40-45 \%$ and $30-35 \%$ of field capacity designated as $\mathrm{W} 1, \mathrm{~W} 2$ and $\mathrm{W} 3$, respectively), thus producing 9 temperature-soil moisture content combinations expressed as W1T1, W2T1, W3T1, W1T2, W2T2, W3T2, W1T3, W2T3 and W3T3 was performed in phytotrons to allow accurate environmental control and the assessment of flavonoid accumulation and their biosynthesis-related genes expression. The present study focused on the combined effect of the main experimental factors (i.e., the 9 temperature-soil moisture content combinations) as the individual role of either temperature or soil moisture content was assessed previously [17]. Three phytotrons

*Corresponding author: Yousry A EIKassaby, Department of Forest and Conservation Sciences, Faculty of Forestry, University of British Columbia, Vancouver, BC, Canada Tel: +1-(604)822-1821; E-mail: y.el-kassaby@ubc.ca

Received November 04, 2014; Accepted November 18, 2014; Published January 05, 2015

Citation: Wang G, Cao F, Wang G, Yousry A, Kassaby El (2015) Role of Temperature and Soil Moisture Conditions on Flavonoid Production and Biosynthesis-Related Genes in Ginkgo (Ginkgo biloba L.) Leaves. Nat Prod Chem Res 3: 162. doi:10.4172/2329-6836.1000162

Copyright: $\odot 2015$ Wang G, et al. This is an open-access article distributed under the terms of the Creative Commons Attribution License, which permits unrestricted use, distribution, and reproduction in any medium, provided the original author and source are credited. 
Citation: Wang G, Cao F, Wang G, Yousry A, Kassaby El (2015) Role of Temperature and Soil Moisture Conditions on Flavonoid Production and Biosynthesis-Related Genes in Ginkgo (Ginkgo biloba L.) Leaves. Nat Prod Chem Res 3: 162. doi:10.4172/2329-6836.1000162

Page 2 of 6

with identical light conditions were used and each phytotron was set to control a single temperature. Potted 2-year-old Ginkgo seedlings, two at each pot (average height $=33.0 \mathrm{~cm}$ and diameter at ground level $=6.8 \mathrm{~mm}$ ), were transferred to the phytotrons on June, 2011, and the treatments started on July, 2011. Seedlings were grown in 12 $\mathrm{x} 15 \mathrm{~cm}$ (diameter $\mathrm{x}$ height) pots in a 2:1:1 medium consisting of loam, yellow sand, and peat, respectively. The plants received basic nutrients fertilizer as needed.

The day/night temperatures were controlled automatically and soil moisture contents were controlled by weighing method. Randomly sampled leaves from each treatment combination were done at 10 , 20,30, 40 and 50days after the start of treatments. Leaf samples were divided to two parts, one to determine the flavonoid contents and the other to determine relative gene.

\section{Analysis of flavonoid content}

High performance liquid chromatography (HPLC) as described by the Chinese Pharmacopoeia Commission (2010) was used for flavonoid analyses [18]. A $10 \mu \mathrm{l}$ reference solution (30 $\mu \mathrm{g}$ quercetin, 30 $\mu \mathrm{g}$ kaempferol, $20 \mu \mathrm{g}$ isorhamnetin, and $1 \mathrm{~mL}$ methanol) and extract solution were transferred into liquid chromatograph (Waters 2695, USA) and the contents of quercetin, kaempferol and isorhamnetin were determined. Flavonoids totals $=($ (quercetin content + kaempferol content + isorhamnetin content $) \times 2.51)$. Statistical significance was evaluated using the Tukey-Kramer test.

\section{Expression analysis of flavonoid biosynthesis-related genes}

Total RNA was isolated from the leaf samples (three samples for each treatment) following the method of [9] and cDNAs were synthesized using a cDNA synthesis kit (Clontech, USA) following the manufacturers' manuals. We determined the expression levels of flavonoid biosynthesis-related genes, including PAL (phenylalanine ammonia-lyase), CHS (chalcone synthase), F3H (flavanone 3-hydroxylase), ANR (anthocyanidinreductase), FLS (flavonol synthase), C4H (cinnamate-4-hydroxylase), and ANS (anthocyanidin synthase), together with a fragment of GADPH (glyceraldehyde3-phosphate dehydrogenase) coding glyceraldehyde-3-phosphate dehydrogenase as a reference gene by quantitative real-time PCR (qRT-PCR) using an ABI PRISM 7500 Sequence Detection System (Applied Biosystems, Foster City, CA, USA) and a SYBR Green PCR Master Mix (Applied Biosystems, Foster City, CA, USA) following the manufacturers' manuals [20] (Table 1). An actin gene, having constant

\begin{tabular}{|c|c|c|}
\hline Gene name & Sequence $\left(5^{\prime} \rightarrow 3^{\prime}\right)$ & $\operatorname{Tm}\left({ }^{\circ} \mathbf{C}\right)$ \\
\hline \multirow{2}{*}{ PAL } & Up-5'GCGCTGCGGACTCAATCT3' & 58 \\
\hline & Down-5'GCCCATCCATTGATTCATAGGA3' & 51 \\
\hline \multirow{2}{*}{$\mathrm{C} 4 \mathrm{H}$} & Up-5'TGATGTTTGATAGGCGGTTTGA3' & 51 \\
\hline & Down-5'AGGCCTTAAGCYYGAGGAACAA3' & 51 \\
\hline \multirow{2}{*}{$\mathrm{CHS}$} & Up-5'CAGCGAATACGGCAACATGT3' & 60 \\
\hline & Down-5'CGCATTTCGTCGAGGATGA3' & 58 \\
\hline \multirow{2}{*}{$\mathrm{F} 3 \mathrm{H}$} & Up-5'GGCCCAAAGTGGCGTACA3' & 58 \\
\hline & Down-5'TCCGGCCAGTGAGATTATGG3' & 62 \\
\hline \multirow{2}{*}{ FLS } & Up-5'AGCCACGCACACTGTAATGG3' & 62 \\
\hline & Down-5'GGCGGCTTTCTGCAACATAT3' & 60 \\
\hline \multirow{2}{*}{ ANS } & Up-5'CCTTCTTCGACCTCCССАTT3' & 62 \\
\hline & Down-5'CCGGAGGCGGAGTCAAA3' & 56 \\
\hline \multirow{2}{*}{ ANR } & Up-5'CCGGCCGTGACACCAA3' & 54 \\
\hline & Down-5'AATCAGCGACAGGGCAAGTT3' & 60 \\
\hline \multirow{2}{*}{ GAPDH } & Up-5'GGTGCCAAAAAGGTGGTCAT3' & 60 \\
\hline & Down-5'CAACAACGAACATGGGAGCAT3' & 49.6 \\
\hline
\end{tabular}

Table 1: Primers used for the quantification of gene expression levels by qRT-PCR. expression levels (data not shown), was used to normalize the raw data and to calculate the relative transcript levels. Statistical significance was evaluated using the Tukey-Kramer test.

\section{Results}

\section{Total flavonoid content of ginkgo leaves}

The temperature and soil moisture content had significant effects on total flavonoid content of Ginkgo leaves (Table 2). Additionally, all first-order interactions were significant, thus requiring interpretation based on observing the 9 temperature-soil moisture content means (Table 3). Generally, total flavonoid content varied among treatments and was substantially influenced by the treatment duration. For example, W2T1 and W3T1 produced the lowest and highest $(p<0.001)$ flavonoid content under $10-30 \mathrm{~d}$ and $40-50 \mathrm{~d}$ treatments, respectively (Table 3), suggesting that a treatment combination of low temperature (T1) coupled with medium to low soil moisture content (W2 or W3) is beneficial to the biosynthesis and accumulation of flavonoid in Ginkgo leaves. Additionally, we observed gradual decrease in total flavonoid content with increasing of temperature at the same soil moisture content (Table 3). The mean flavonoid content across different soil moisture content and duration treatments under T1, T2, and T3 were $15.3,12.4$, and $9.9 \mathrm{mg} / \mathrm{g}$, respectively, indicating that lower temperature is conducive to flavonoid biosynthesis and accumulation in Ginkgo leaves. It should also be highlighted that at the same temperature condition, the total flavonoid content produced under different soil moisture contents varied and did not produce any obvious trend and the observed trend for temperature was not duplicated for soil moisture content as the mean flavonoid content across $\mathrm{W} 1, \mathrm{~W} 2$, and W3 and duration were $12.25,12.13$, and $13.22 \mathrm{mg} / \mathrm{g}$, respectively, suggesting that lower soil moisture content is favorable but the effect is not as pronounced as that of temperature. The total flavonoid content of the same temperature-soil moisture content treatment combination also had significant variation at different treatment time, and generally the 40- and 50d durations produced higher total flavonoid content, highlighting the positive role of prolonging treatment time on flavonoid accumulation.

\section{The expression level of flavonoid biosynthesis-related upstream genes and their relationship with flavonoid accumulation}

Temperature and soil moisture content treatment combinations and their duration, all affected the expression level of $\mathrm{C} 4 \mathrm{H}$ and CHS genes significantly, but the effect of soil moisture content on the expression of PAL gene was not significant (Tables 2 and 4). All temperature-soil moisture content treatment combinations within the various treatments duration flavonoid expression levels did not produce clear trend(s) for total flavonoids and any generalization was difficult to discern (supplementary material).

At the same soil moisture content, the expression level of PAL, $\mathrm{C} 4 \mathrm{H}$, and $\mathrm{CHS}$ genes gradually declined with increasing of temperature (Table 4). At the same temperature, the PAL and C4H expression levels were highest at $\mathrm{W} 3$ while $\mathrm{W} 1$ produced the highest gene expression for CHS. Generally, under the three temperatures used, the mean PAL, $\mathrm{C} 4 \mathrm{H}$, and $\mathrm{CHS}$ gene expression of different soil moisture treatments declined (PAL: 1.41, 1.16, 0.96 (T1, T2, T3); C4H: 1.47, 1.08, 0.93; CHS: $1.85,1.61$ and 0.88 ), indicating that lower temperature is conducive for their expression in Ginkgo leaves. On the other hand, under the three studied soil moisture contents, the mean PAL, C4H, and CHS gene expression of different temperature treatments produced different trends (PAL: 1.19, 1.15, 1.20 (W1, W2, W3); C4H: 1.11, 1.02, 1.35; CHS: $1.83,1.23,1.28)$, suggesting that lower soil moisture is favorable 
Citation: Wang G, Cao F, Wang G, Yousry A, Kassaby El (2015) Role of Temperature and Soil Moisture Conditions on Flavonoid Production and Biosynthesis-Related Genes in Ginkgo (Ginkgo biloba L.) Leaves. Nat Prod Chem Res 3: 162. doi:10.4172/2329-6836.1000162

Page 3 of 6

\begin{tabular}{|c|c|c|c|c|c|c|c|c|c|}
\hline \multicolumn{2}{|c|}{ Index } & Total flavonoid & PAL & $\mathrm{C} 4 \mathrm{H}$ & CHS & F3H & FLS & ANS & ANR \\
\hline \multirow{2}{*}{$\mathrm{T}$} & $F$-value & 165.037 & 150.534 & 184.104 & 245.059 & 37.560 & 52.049 & 113.080 & 43.006 \\
\hline & $P$-value & $<0.001$ & $<0.001$ & $<0.001$ & $<0.001$ & $<0.001$ & $<0.001$ & $<0.001$ & $<0.001$ \\
\hline \multirow{2}{*}{ W } & $F$-value & 10.543 & 2.790 & 68.632 & 104.980 & 72.177 & 28.897 & 38.344 & 25.767 \\
\hline & $P$-value & $<0.001$ & 0.067 & $<0.001$ & $<0.001$ & $<0.001$ & $<0.001$ & $<0.001$ & $<0.001$ \\
\hline \multirow{2}{*}{ D } & $F$-value & 70.894 & 126.152 & 74.366 & 738.151 & 65.413 & 115.186 & 184.042 & 34.783 \\
\hline & $P$-value & $<0.001$ & $<0.001$ & $<0.001$ & $<0.001$ & $<0.001$ & $<0.001$ & $<0.001$ & $<0.001$ \\
\hline \multirow{2}{*}{$T \times W$} & $F$-value & 10.55 & 4.555 & 4.444 & 15.933 & 1.931 & 0.435 & 28.813 & 18.668 \\
\hline & $P$-value & $<0.001$ & 0.002 & 0.003 & $<0.001$ & 0.112 & 0.783 & $<0.001$ & $<0.001$ \\
\hline \multirow{2}{*}{$T \times D$} & $F$-value & 9.79 & 15.531 & 19.419 & 220.551 & 10.032 & 7.892 & 25.599 & 32.247 \\
\hline & $P$-value & $<0.001$ & $<0.001$ & $<0.001$ & $<0.001$ & $<0.001$ & $<0.001$ & $<0.001$ & $<0.001$ \\
\hline \multirow{2}{*}{$W \times D$} & $F$-value & 4.372 & 9.687 & 12.108 & 80.836 & 39.808 & 6.711 & 24.508 & 15.729 \\
\hline & $P$-value & $<0.001$ & $<0.001$ & $<0.001$ & $<0.001$ & $<0.001$ & $<0.001$ & $<0.001$ & $<0.001$ \\
\hline \multirow{2}{*}{$T \times W \times D$} & $F$-value & 1.106 & 7.320 & 6.900 & 40.183 & 14.725 & 8.964 & 17.309 & 22.574 \\
\hline & $P$-value & 0.362 & $<0.001$ & $<0.001$ & $<0.001$ & $<0.001$ & $<0.001$ & $<0.001$ & $<0.001$ \\
\hline
\end{tabular}

Table 2: Three-way analysis of variance showing the effects of temperature $(T)$, soil moisture $(W)$, treatments time $(D)$, and their interactions $(T \times W, T \times D, W \times D$, and $T \times W \times D)$ on total flavonoid content and their expression level for seven flavonoid biosynthesis-related genes.

\begin{tabular}{|c|c|c|c|c|c|c|c|c|}
\hline Treatment time (day) & $10 \mathrm{~d}$ & 20d & $30 d$ & $40 d$ & $50 d$ & Mean & $F$-value & $P$-value \\
\hline W1T1 & $12.36 \pm 0.13 b c$ & $14.10 \pm 0.14 b c$ & $13.26 \pm 0.11 c$ & $16.77 \pm 0.10 \mathrm{bc}$ & $13.74 \pm 0.12 c$ & 14.05 & 10.47 & 0.0013 \\
\hline W2T1 & $13.19 \pm 0.14 a$ & $15.74 \pm 0.12 a$ & $14.23 \pm 0.11 a$ & $17.60 \pm 0.16 b$ & $16.90 \pm 0.17 b$ & 15.53 & 63.67 & 0.0001 \\
\hline W3T1 & $12.45 \pm 0.11 b$ & $14.80 \pm 0.13 b$ & $13.82 \pm 0.14 b$ & $19.39 \pm 0.17 a$ & $20.37 \pm 0.16 a$ & 16.16 & 23.91 & 0.0001 \\
\hline W1T2 & $10.81 \pm 0.12 d$ & $13.52 \pm 0.13 c$ & $12.69 \pm 0.11 \mathrm{de}$ & $15.90 \pm 0.13 c$ & $8.60 \pm 0.09 e$ & 12.30 & 158.82 & 0.0001 \\
\hline W2T2 & $10.45 \pm 0.11 d$ & $12.41 \pm 0.12 \mathrm{~d}$ & $12.99 \pm 0.13 \mathrm{~cd}$ & $15.62 \pm 0.14 c$ & $9.91 \pm 0.08 d$ & 12.28 & 110.72 & 0.0001 \\
\hline W3T2 & $12.19 \pm 0.11 b c$ & $13.90 \pm 0.12 c$ & $12.37 \pm 0.13$ ef & $13.28 \pm 0.11 d$ & $11.09 \pm 0.11 d$ & 12.57 & 46.30 & 0.0001 \\
\hline W1T3 & $10.61 \pm 0.09 d$ & $9.09 \pm 0.08 f$ & $11.22 \pm 0.12 g$ & $12.79 \pm 0.09 d$ & $8.30 \pm 0.08 \mathrm{e}$ & 10.43 & 80.44 & 0.0001 \\
\hline W2T3 & $8.67 \pm 0.07 e$ & $9.50 \pm 0.06 \mathrm{ef}$ & $9.16 \pm 0.08 h$ & $9.79 \pm 0.10 e$ & $5.87 \pm 0.05 f$ & 8.60 & 146.97 & 0.0001 \\
\hline W3T3 & $11.73 \pm 0.09 c$ & $10.21 \pm 0.08 e$ & $11.99 \pm 0.12 f$ & $10.75 \pm 0.11 \mathrm{e}$ & $9.89 \pm 0.08 d$ & 10.91 & 15.86 & 0.0002 \\
\hline$F$-value & 21.39 & 8.85 & 64.73 & 9.61 & 18.07 & & & \\
\hline$P$-value & 0.0001 & 0.0004 & 0.0001 & 0.0002 & 0.0001 & & & \\
\hline
\end{tabular}

Table 3: Total flavonoid content in $\mathrm{mg} \cdot \mathrm{g}-1$ (mean $\pm \mathrm{SD}$ ) in Ginkgo leaf across five durations (10d to 50d) under nine temperature - soil moisture treatments. Means with different letters are significantly different at $P<0.05$. (see Material and Methods for treatments designation).

\begin{tabular}{|c|c|c|c|c|c|c|c|c|c|c|}
\hline Name & Time & W1T1 & W2T1 & W3T1 & W1T2 & W2T2 & W3T2 & W1T3 & W2T3 & W3T3 \\
\hline \multirow{5}{*}{ PAL } & $10 d$ & $1.00 \pm 0.12$ & $0.90 \pm 0.08$ & $0.87 \pm 0.1$ & $0.70 \pm 0.06$ & $0.88 \pm 0.15$ & $0.80 \pm 0.10$ & $0.65 \pm 0.08$ & $0.40 \pm 0.05$ & $0.79 \pm 0.09$ \\
\hline & $20 d$ & $1.41 \pm 0.19$ & $1.14 \pm 0.13$ & $1.65 \pm 0.16$ & $1.22 \pm 0.12$ & $0.92 \pm 0.15$ & $1.55 \pm 0.15$ & $0.64 \pm 0.09$ & $0.90 \pm 0.12$ & $0.83 \pm 0.11$ \\
\hline & $30 d$ & $1.40 \pm 0.12$ & $1.09 \pm 0.12$ & $1.16 \pm 0.11$ & $0.88 \pm 0.06$ & $1.50 \pm 0.16$ & $1.08 \pm 0.14$ & $1.18 \pm 0.11$ & $1.09 \pm 0.09$ & $1.22 \pm 0.11$ \\
\hline & $40 d$ & $1.75 \pm 0.15$ & $1.88 \pm 0.11$ & $1.64 \pm 0.12$ & $1.70 \pm 0.11$ & $1.56 \pm 0.12$ & $1.35 \pm 0.13$ & $1.46 \pm 0.14$ & $1.21 \pm 0.10$ & $0.98 \pm 0.09$ \\
\hline & $50 d$ & $1.71 \pm 0.10$ & $1.52 \pm 0.16$ & $2.05 \pm 0.2$ & $1.02 \pm 0.12$ & $1.11 \pm 0.19$ & $1.22 \pm 0.13$ & $1.06 \pm 0.11$ & $1.10 \pm 0.11$ & $0.92 \pm 0.09$ \\
\hline \multirow{5}{*}{$\mathrm{C} 4 \mathrm{H}$} & $10 d$ & $1.92 \pm 0.08$ & $1.46 \pm 0.12$ & $1.70 \pm 0.14$ & $1.19 \pm 0.20$ & $0.99 \pm 0.26$ & $1.44 \pm 0.27$ & $1.10 \pm 0.12$ & $0.68 \pm 0.08$ & $1.43 \pm 0.17$ \\
\hline & $20 d$ & $2.25 \pm 0.19$ & $1.81 \pm 0.11$ & $2.28 \pm 0.21$ & $1.40 \pm 0.19$ & $1.26 \pm 0.23$ & $1.11 \pm 0.23$ & $0.98 \pm 0.16$ & $0.87 \pm 0.11$ & $1.25 \pm 0.17$ \\
\hline & $30 d$ & $0.81 \pm 0.09$ & $0.97 \pm 0.10$ & $1.15 \pm 0.13$ & $0.69 \pm 0.06$ & $0.72 \pm 0.07$ & $1.58 \pm 0.09$ & $0.54 \pm 0.08$ & $0.66 \pm 0.07$ & $1.37 \pm 0.08$ \\
\hline & $40 d$ & $1.12 \pm 0.10$ & $1.37 \pm 0.06$ & $1.35 \pm 0.10$ & $1.17 \pm 0.07$ & $0.88 \pm 0.14$ & $1.01 \pm 0.12$ & $0.70 \pm 0.06$ & $1.11 \pm 0.10$ & $1.21 \pm 0.20$ \\
\hline & $50 d$ & $1.09 \pm 0.10$ & $1.01 \pm 0.07$ & $1.78 \pm 0.17$ & $0.98 \pm 0.08$ & $0.85 \pm 0.12$ & $0.88 \pm 0.17$ & $0.61 \pm 0.03$ & $0.7 \pm 0.07$ & $0.73 \pm 0.13$ \\
\hline \multirow{5}{*}{$\mathrm{CHS}$} & $10 \mathrm{~d}$ & $5.55 \pm 0.56$ & $0.73 \pm 0.38$ & $2.92 \pm 0.52$ & $1.51 \pm 0.51$ & $0.61 \pm 0.13$ & $0.33 \pm 0.35$ & $1.92 \pm 0.14$ & $0.08 \pm 0.01$ & $1.65 \pm 0.10$ \\
\hline & $20 d$ & $5.83 \pm 0.20$ & $3.92 \pm 0.07$ & $3.16 \pm 0.05$ & $4.67 \pm 0.55$ & $4.92 \pm 0.12$ & $4.00 \pm 0.04$ & $1.08 \pm 0.42$ & $0.80 \pm 0.11$ & $0.83 \pm 0.36$ \\
\hline & $30 d$ & $0.01 \pm 0.00$ & $0.07 \pm 0.01$ & $0.09 \pm 0.02$ & $0.02 \pm 0.00$ & $0.21 \pm 0.01$ & $0.17 \pm 0.01$ & $0.18 \pm 0.02$ & $0.06 \pm 0.00$ & $1.23 \pm 0.01$ \\
\hline & $40 d$ & $0.98 \pm 0.15$ & $0.75 \pm 0.06$ & $0.35 \pm 0.20$ & $1.66 \pm 0.06$ & $0.80 \pm 0.08$ & $2.02 \pm 0.10$ & $2.08 \pm 0.29$ & $1.67 \pm 0.26$ & $0.25 \pm 0.15$ \\
\hline & $50 d$ & $0.29 \pm 0.14$ & $2.06 \pm 0.06$ & $1.08 \pm 0.11$ & $1.42 \pm 0.02$ & $0.75 \pm 0.24$ & $1.04 \pm 0.03$ & $0.23 \pm 0.02$ & $1.02 \pm 0.25$ & $0.06 \pm 0.02$ \\
\hline
\end{tabular}

Table 4: The expression level of flavonoid biosynthesis-related upstream genes (mean \pm SD) in Ginkgo leaf across five durations (10d to $50 \mathrm{~d}$ ) less than nine temperature - soil moisture treatments. (See Material and Methods for treatments designation).

for $\mathrm{C} 4 \mathrm{H}$, higher soil moisture is beneficial for CHS, and soil moisture has no obvious effect on PAL gene expression (Table 2 and 4 ).

\section{The expression level of flavonoid biosynthesis-related downstream genes and their relationship with the flavonoid accumulation}

Temperature and soil moisture content as well as treatments duration, all significantly affected the expression level of the flavonoid biosynthesisrelated downstream genes (F3H, FLS, ANS, and ANR); however, the expression level varied across the same temperature-soil moisture combinations (Table 2 and 5). Additionally, prolonging treatment time was not associated with any clear increasing or decreasing trends across the four studied genes, indicating that a particular treatment combination (i.e., interaction) is required for each specific gene.

\section{Discussion}

The flavonoid family is divided into six main classes; namely, 
Citation: Wang G, Cao F, Wang G, Yousry A, Kassaby El (2015) Role of Temperature and Soil Moisture Conditions on Flavonoid Production and Biosynthesis-Related Genes in Ginkgo (Ginkgo biloba L.) Leaves. Nat Prod Chem Res 3: 162. doi:10.4172/2329-6836.1000162

Page 4 of 6

\begin{tabular}{|c|c|c|c|c|c|c|c|c|c|c|}
\hline Name & Time & W1T1 & W2T1 & W3T1 & W1T2 & W2T2 & W3T2 & W1T3 & W2T3 & W3T3 \\
\hline \multirow{5}{*}{$\mathrm{F} 3 \mathrm{H}$} & $10 d$ & $0.99 \pm 0.10$ & $1.12 \pm 0.08$ & $1.00 \pm 0.09$ & $0.79 \pm 0.07$ & $0.63 \pm 0.12$ & $1.05 \pm 0.08$ & $0.61 \pm 0.09$ & $0.83 \pm 0.09$ & $0.80 \pm 0.09$ \\
\hline & $20 d$ & $1.02 \pm 0.17$ & $1.03 \pm 0.11$ & $1.71 \pm 0.14$ & $1.22 \pm 0.08$ & $0.67 \pm 0.12$ & $1.35 \pm 0.19$ & $1.09 \pm 0.17$ & $1.00 \pm 0.12$ & $1.11 \pm 0.14$ \\
\hline & $30 d$ & $0.85 \pm 0.12$ & $1.19 \pm 0.08$ & $1.24 \pm 0.06$ & $1.32 \pm 0.04$ & $0.91 \pm 0.01$ & $1.02 \pm 0.08$ & $0.82 \pm 0.08$ & $0.55 \pm 0.04$ & $0.77 \pm 0.02$ \\
\hline & $40 d$ & $1.54 \pm 0.10$ & $1.11 \pm 0.06$ & $1.17 \pm 0.07$ & $1.12 \pm 0.09$ & $1.31 \pm 0.09$ & $1.16 \pm 0.08$ & $1.04 \pm 0.06$ & $1.19 \pm 0.08$ & $1.38 \pm 0.11$ \\
\hline & $50 d$ & $0.47 \pm 0.02$ & $0.96 \pm 0.12$ & $1.34 \pm 0.01$ & $0.16 \pm 0.02$ & $1.23 \pm 0.08$ & $0.94 \pm 0.10$ & $0.49 \pm 0.17$ & $1.04 \pm 0.14$ & $1.29 \pm 0.19$ \\
\hline \multirow{5}{*}{ FLS } & $10 d$ & $0.66 \pm 0.09$ & $0.94 \pm 0.09$ & $0.85 \pm 0.11$ & $0.74 \pm 0.06$ & $0.73 \pm 0.12$ & $0.86 \pm 0.05$ & $0.70 \pm 0.10$ & $0.77 \pm 0.09$ & $1.03 \pm 0.10$ \\
\hline & $20 d$ & $0.93 \pm 0.12$ & $1.05 \pm 0.08$ & $1.12 \pm 0.10$ & $0.89 \pm 0.09$ & $0.82 \pm 0.12$ & $1.02 \pm 0.11$ & $0.27 \pm 0.07$ & $0.82 \pm 0.11$ & $0.70 \pm 0.11$ \\
\hline & $30 d$ & $0.97 \pm 0.06$ & $0.95 \pm 0.09$ & $1.04 \pm 0.08$ & $0.57 \pm 0.06$ & $1.06 \pm 0.13$ & $1.00 \pm 0.07$ & $0.90 \pm 0.14$ & $0.49 \pm 0.04$ & $0.99 \pm 0.04$ \\
\hline & $40 d$ & $1.39 \pm 0.11$ & $1.41 \pm 0.07$ & $1.34 \pm 0.09$ & $1.22 \pm 0.09$ & $1.28 \pm 0.11$ & $1.20 \pm 0.10$ & $1.33 \pm 0.11$ & $1.16 \pm 0.10$ & $1.13 \pm 0.07$ \\
\hline & $50 d$ & $1.24 \pm 0.11$ & $1.06 \pm 0.07$ & $1.46 \pm 0.11$ & $1.09 \pm 0.09$ & $0.90 \pm 0.11$ & $1.18 \pm 0.09$ & $0.84 \pm 0.11$ & $1.08 \pm 0.12$ & $1.01 \pm 0.14$ \\
\hline \multirow{5}{*}{ ANS } & $10 d$ & $0.97 \pm 0.12$ & $1.01 \pm 0.10$ & $0.98 \pm 0.13$ & $0.84 \pm 0.09$ & $1.11 \pm 0.16$ & $0.93 \pm 0.11$ & $1.06 \pm 0.13$ & $0.69 \pm 0.08$ & $1.10 \pm 0.13$ \\
\hline & $20 d$ & $0.97 \pm 0.13$ & $0.78 \pm 0.09$ & $0.96 \pm 0.14$ & $0.98 \pm 0.08$ & $0.55 \pm 0.09$ & $0.47 \pm 0.06$ & $0.51 \pm 0.07$ & $0.72 \pm 0.10$ & $0.79 \pm 0.11$ \\
\hline & $30 d$ & $0.86 \pm 0.08$ & $0.91 \pm 0.06$ & $1.26 \pm 0.12$ & $1.47 \pm 0.09$ & $0.84 \pm 0.09$ & $0.54 \pm 0.05$ & $1.39 \pm 0.13$ & $0.72 \pm 0.06$ & $1.83 \pm 0.16$ \\
\hline & $40 d$ & $2.08 \pm 0.13$ & $2.19 \pm 0.16$ & $1.30 \pm 0.13$ & $1.59 \pm 0.10$ & $1.02 \pm 0.11$ & $0.81 \pm 0.07$ & $1.90 \pm 0.12$ & $2.00 \pm 0.11$ & $1.40 \pm 0.13$ \\
\hline & $50 d$ & $1.44 \pm 0.20$ & $0.80 \pm 0.06$ & $1.35 \pm 0.14$ & $0.77 \pm 0.05$ & $0.91 \pm 0.11$ & $0.14 \pm 0.01$ & $1.29 \pm 0.19$ & $1.29 \pm 0.19$ & $1.21 \pm 0.22$ \\
\hline \multirow{5}{*}{ ANR } & $10 d$ & $0.80 \pm 0.10$ & $0.61 \pm 0.09$ & $0.71 \pm 0.12$ & $0.81 \pm 0.07$ & $0.77 \pm 0.15$ & $0.62 \pm 0.10$ & $0.91 \pm 0.11$ & $0.68 \pm 0.08$ & $1.10 \pm 0.13$ \\
\hline & $20 d$ & $0.92 \pm 0.12$ & $0.95 \pm 0.07$ & $0.87 \pm 0.13$ & $0.96 \pm 0.09$ & $1.08 \pm 0.12$ & $0.87 \pm 0.08$ & $1.03 \pm 0.15$ & $0.84 \pm 0.11$ & $0.22 \pm 0.13$ \\
\hline & $30 d$ & $0.85 \pm 0.07$ & $0.91 \pm 0.07$ & $0.84 \pm 0.08$ & $0.12 \pm 0.01$ & $1.22 \pm 0.13$ & $0.74 \pm 0.06$ & $1.39 \pm 0.13$ & $0.68 \pm 0.06$ & $1.36 \pm 0.02$ \\
\hline & $40 d$ & $1.39 \pm 0.12$ & $1.03 \pm 0.07$ & $0.87 \pm 0.08$ & $1.27 \pm 0.08$ & $0.88 \pm 0.09$ & $0.88 \pm 0.08$ & $1.05 \pm 0.10$ & $1.23 \pm 0.11$ & $0.93 \pm 0.08$ \\
\hline & $50 d$ & $1.08 \pm 0.11$ & $0.97 \pm 0.02$ & $1.03 \pm 0.07$ & $0.58 \pm 0.04$ & $0.65 \pm 0.08$ & $0.18 \pm 0.02$ & $1.08 \pm 0.11$ & $0.91 \pm 0.09$ & $0.86 \pm 0.13$ \\
\hline
\end{tabular}

Table 5: The expression level of flavonoid biosynthesis-related downstream genes (mean $\pm \mathrm{SD}$ ) in Ginkgo leaf across five durations (10d to $50 \mathrm{~d})$ under nine temperature soil moisture treatments. (see Material and Methods for treatments designation).

flavonols, flavones, lavan-3-ols, isoflavones, flavanones, and anthocyanidins [21]. The metabolism of flavonoids follows a complex pathway, and some environmental factors such as temperature, water status, light condition, and nitrogen all have been demonstrated to affect flavonoids accumulation [22-25]. The present study demonstrated that lower temperature and to a lesser extent lower soil moisture content is favourable to flavonoid accumulation in Ginkgo leaves, and more specifically $\mathrm{W} 2 \mathrm{~T} 1$ and $\mathrm{W} 3 \mathrm{~T} 1$ treatments produced the highest total flavonoid content (Table 3). Studies related to temperature effect on flavonoid content in other plants generally concluded that lower temperature is beneficial to the biosynthesis and accumulation of flavonoid supporting our observations. For example, elevated bunch temperature was associated with total anthocyanin, proanthocyanidin, and quercetinconcentrations reduction in grape berry skins (Vitis vinifera cv. Merlot and Cabernet-Sauvignon [26-27]). Similar observation was made in maize (Zea mays) where seedlings growing under short-term, low-temperature treatment showed substantial changes in anthocyanin content [4]. Modeling flavonoid biosynthesis and degradation indicated that they are sensitive to temperature [24]. Conversely, the role of soil moisture on flavonoid content in plants did not produce uniform results. For example, water stress resulted in increasing the expression of anthocyanin biosynthetic pathway genes in grape berries; however, with limited effect on the biosynthesis of proanthocyanidin and flavonol[6]. Opposite trend was observed for epigallocatechingallate, ascorbic acid, and $\alpha$-tocopherol concentrations of Cistus clusii leaves which increased by 2.8, 2.6, and 3.3 fold; respectively, in response to drought stress [22]. Finally, no clear trend was detected for leaf polyphenol concentrations in Ligustrum vulgare leaves under reduced water treatment [28].

Flavonoid biosynthesis in Ginkgo leaves requires coordinated expression of genes encoding enzymes in the core phenylpropanoid pathway, such as PAL and 4-coumarate CoA ligase, and enzymes in branch pathways, such as $\mathrm{CHS}$ and $\mathrm{CHI}$ (chalconeisomerase). These genes are divided into structural genes that encode the key enzymes of the flavonoid pathway and regulatory genes that are required for flavonoid biosynthesis. The structural genes are separated into upstream genes, such as $\mathrm{PAL}, \mathrm{C} 4 \mathrm{H}, \mathrm{CHS}$, and $\mathrm{CHI}$, which catalyze the process from phenylalanine to hydroxycinnamic acid and 4-Coumaroyl-CoA, and downstream genes, such as F3H, FLS, ANS, and ANR, which catalyze the process from 4-Coumaroyl-CoA to flavonoids. PAL is a link between primary and secondary metabolism and high PAL expression is often found in parallel with high levels of flavonoids [29]. In our study, we found PAL expression levels at $15 / 5^{\circ} \mathrm{C}$ (day/night) was 1.46 and 1.20 times than that at $35 / 25$ and $25 / 15^{\circ} \mathrm{C}$, respectively, while PAL expression levels at different soil moisture content treatments did not differ as they were not significantly different from each other (Table 3). We also found that the changing trend of PAL expression in different treatments at different durations were identical with that of flavonoid content, and higher PAL expression coincided with higher flavonoid content. These results imply that lower temperature improves the expression of PAL gene, while soil moisture content has a negligible effect on its expression, as evident by the clear relation between PAL expression and the biosynthesis of flavonoid. Similar observations of PAL increased expression were reported after exposure to low temperature in Arabidopsis thaliana leaves [30] and tomato (Solanum lycopersicum) plants [31]. Additionally, the unclear role of moisture effect on PAL gene expression was also supported by the conflicting observations in Camellia sinensis [32] and Scutellaria baicalensis [33] which showed decreased and increased PAL expression under water deficit conditions, respectively.

$\mathrm{C} 4 \mathrm{H}$ and $\mathrm{CHS}$, the other two upstream genes of flavonoid biosynthesis are well investigated as $\mathrm{C} 4 \mathrm{H}$ is the key enzyme in the second step of phenylpropanoid pathway as it controls the synthesis of $\rho$-coumaric acid from trans-cinnamic acid [34], while CHS is known to encode the first committed enzyme in flavonoid biosynthesis. CHS has been used extensively as a model for identifying and studying elements controlling the expression of flavonoid biosynthetic genes [5]. In the present study, we found lower temperature to be conducive for the expression of $\mathrm{C} 4 \mathrm{H}$ and $\mathrm{CHS}$ genes in Ginkgo leaves as total flavonoid content was highest at lower temperature. Treatment duration; however, tended to change $\mathrm{C} 4 \mathrm{H}$ and $\mathrm{CHS}$ gene expression as their expression levels were consistent with total flavonoid content, 
Citation: Wang G, Cao F, Wang G, Yousry A, Kassaby El (2015) Role of Temperature and Soil Moisture Conditions on Flavonoid Production and Biosynthesis-Related Genes in Ginkgo (Ginkgo biloba L.) Leaves. Nat Prod Chem Res 3: 162. doi:10.4172/2329-6836.1000162

further supporting the close relation between flavonoids biosynthesis and $\mathrm{C} 4 \mathrm{H}$ and $\mathrm{CHS}$ expression. Similar results were reported in grape skin (V. labruscana) [7] and tomato plants (Solanum lycopersicum cv. Suzanne) [31] showing increased CHS expression in response to lower temperatures. Our results also demonstrated the presence of consistent relationship between soil moisture and $\mathrm{C} 4 \mathrm{H}$ expression and flavonoid content (i.e., higher expression under lower soil moisture) as well as the lack of relationship for CHS as expression was higher under high soil moisture, results are at variance with what has been reported in Camellia sinensis [32] and Scutellaria baicalensis [33] in which increased expression was reported under water deficit.

F3H, FLS, ANS, and ANR are downstream genes of flavonoid biosynthesis, which catalyze hydroxyl cinnamoyl CoA to generate different kinds of flavonoids. $\mathrm{F} 3 \mathrm{H}$ is a key enzyme at a diverging point of flavonoid pathway leading to the production of different pigments, such as phlobaphene, proanthocyanidin, and anthocyanin. FLS is an essential enzyme of flavonols biosynthesis as it converts dihydrokaempferol or dihydroquercetin to the corresponding flavonols, kaempferol and quercetin, respectively, and it has a close relation with the accumulation of flavonols. ANS and ANR play important role in anthocyanidin and proanthocyanidin biosynthesis, respectively, and both affect flavonoid biosynthesis and their content in plants. Our results showed that the best temperature and soil moisture conditions to stimulate the expression of these downstream genes are different and F3H, FLS, ANS, and ANR preferred different combinations (i.e., interaction). $\mathrm{F} 3 \mathrm{H}$ and FLS favoured lower, ANR responded well to higher, while ANS reacted similarly to both low and high temperature. The same scenario was observed to soil moisture with FLS and F3H favouring low and ANS and ANR responded well to high soil moisture content. Similar results were reported for F3H and FLS genes with increased expression in grape berries under water deficit [6].

\section{Conclusion}

The present study demonstrated that temperature and soil moisture content, to a lesser extent, has significant effects on the accumulation of flavonoid and gene expression of flavonoid biosynthesis. Total flavonoid content was higher in lower temperature and lower soil moisture content in Ginkgo leaves, and that flavonoid biosynthesisrelated genes were up-regulated by lower or higher temperature as well as lower or higher soil moisture, suggesting that temperature and soil water content have a synergistic effect on the expression of genes within the flavonoid biosynthesis pathway. These results should contribute to a complete understanding of the relationships between environmental factors and flavonoid accumulation in Ginkgo leaves.

\section{Acknowledgement}

We thank the National Natural Science Foundation of China, The Science and Technology Department of China, and The State Forestry Bureau.

\section{References}

1. Bohm B (1998) Introduction of flavonoids. Introduction to Flavonoids 1-503.

2. Winkel-Shirley B (2002) Biosynthesis of flavonoids and effects of stress. CurrOpin Plant Biol 5: 218-223.

3. Rice-Evans CA, Miller NJ, Paganga G (1996) Structure-antioxidant activity relationships of flavonoids and phenolic acids. Free RadicBiol Med 20: 933-956.

4. Christie PJ, Alfenito MR, Walbot V (1994) Impact of low-temperature stress on general phenylpropanoid and anthocyanin pathways: Enhancement of transcript abundance and anthocyanin pigmentation in maize seedlings. Planta 194: 541-549.

5. Kubasek WL, AusubelFM, Shirley BW (1998)A light-independent developmental mechanism potentiates flavonoid gene expression in Arabidopsis seedlings. Plant MolBiol 37: 217-223.
6. Castellarin SD, Matthews MA, Di Gaspero G, Gambetta GA (2007) Wate deficits accelerate ripening and induce changes in gene expression regulating flavonoid biosynthesis in grape berries. Planta 227: 101-112.

7. Azuma A, Yakushiji H, Koshita Y, Kobayashi S (2012) Flavonoid biosynthesisrelated genes in grape skin is differentially regulated by temperature and light conditions. Planta 236: 1067-1080.

8. Sparvoli F, Martin C, Scienza A, Gavazzi G, Tonelli C (1994) Cloning and molecular analysis of structural genes involved in flavonoid and stilbene biosynthesis in grape (Vitisvinifera L.). Plant MolBiol 24: 743-755.

9. De Keyser E, De Riek J, Van Bockstaele E (2007) Gene expression profiling of key enzymes in azalea flower colour biosynthesis. ActaHortic 743:115-120.

10. De Schepper S, Debergh P, Van Bocktaele E, De Loose M (2001) Molecular characterisation of flower colour genes in azalea sports (Rhododendron simsii hybrids). ActaHortic 552: 143-150.

11. Jaakola L, Määttä K, Pirttilä AM, Törrönen R, Kärenlampi S, et al. (2002) Expression of genes involved in anthocyanin biosynthesis in relation to anthocyanin, proanthocyanidin, and flavonol levels during bilberry fruit development. Plant Physiol 130: 729-739.

12. Polashock JJ, Griesbach RJ, Sullivan RF, Vorsa N (2002) Cloning of a cDNA encoding the cranberry dihydroflavonol-4-reductase (DFR) and expression in transgenic tobacco. Plant Sci 163: 241-251.

13. Hua C, Linling L, Feng X, Yan W, Honghui Y, et al. (2013) Expression patterns of an isoflavonereductase-like gene and its possible roles in secondary metabolism in Ginkgo biloba. Plant Cell Rep 32: 637-650.

14. vanBeek TA (2002) Chemical analysis of Ginkgo biloba leaves and extracts. $J$ Chromatogr A 967: 21-55.

15. Smith JV, Luo Y (2004) Studies on molecular mechanisms of Ginkgo biloba extract. ApplMicrobiolBiotechnol 64: 465-472.

16. Leng P, Su S, Li Y, Wang S, Jiang X (2001) Effects of fertilizer and drought stress on growth as well as flavonol glycosides and terpene lactone content of Ginkgo biloba seedlings. J Beijing Agric College 16: 32-37.

17. Xu Y, Wang G, Cao F, Zhu C, Wang G, YA El-Kassaby (2014) Light intensity affects the growth and flavonol biosynthesis of Ginkgo (Ginkgo biloba L.). New Forests 45: 765-776

18. (2010) Chinese Pharmacopoeia Commission. Pharmacopoeia of the People's Republic of China. Beijing: Chinese Medical Science and Technology: 243-244.

19. Pang YZ, Shen GA, Wu WS, Liu XF, Lin J, et al. (2005) Characterization and expression of chalcone synthase gene from Ginkgo biloba. Plant Sci 168 1525-1531.

20. Xu F, Cai R, Cheng SY, Du HW, Wang Y, et al. (2008) Molecular cloning characterization and expression of phenylalanine ammonia-lyase gene from Ginkgo biloba. African J Biotechnol 7: 721-729.

21. Jaakola L, Hohtola A (2010) Effect of latitude on flavonoid biosynthesis in plants. Plant Cell Environ 33: 1239-1247.

22. Hernández I, Alegre L, Munné-Bosch S (2004) Drought-induced changes in flavonoids and other low molecular weight antioxidants in Cistusclusii grown under Mediterranean field conditions. Tree Physiol 24: 1303-1311.

23. Albert NW, Lewis DH, Zhang H, Irving LJ, Jameson PE, et al. (2009) Lightinduced vegetative anthocyanin pigmentation in Petunia. $J$ Exp Bot 60: 21912202

24. Olsen KM, Slimestad R, Lea US, Brede C, Løvdal T, et al. (2009) Temperature and nitrogen effects on regulators and products of the flavonoid pathway: experimental and kinetic model studies. Plant Cell Environ 32: 286-299.

25. Steyn WJ, Wand SJ, Jacobs G, Rosecrance RC, Roberts SC (2009) Evidence for a photoprotective function of low-temperature-induced anthocyanin accumulation in apple and pear peel. Physiol Plant 136: 461-472.

26. Tarara JM, Lee J, Spayd SE, Scagel CF (2008) Berry temperature and sola radiation alter acylation, proportion, and concentration of anthocyanin in Merlot grapes. Am J EnolVitic 59: 235-247.

27. Yamamoto GN, Mori K, Numata M, Koyama K, Kitayama M (2010) Effects of temperature and water regimes on flavonoid contents and composition in the skin of red-wine grapes. J IntSciVigne Vin (special issue Macrowine) 75-80.

28. Tattini M, Galardi C, Pinelli P, Massai R, Remorini D, et al. (2004) Differential accumulation of flavonoids and hydroxycinnamates in leaves of 
Citation: Wang G, Cao F, Wang G, Yousry A, Kassaby El (2015) Role of Temperature and Soil Moisture Conditions on Flavonoid Production and Biosynthesis-Related Genes in Ginkgo (Ginkgo biloba L.) Leaves. Nat Prod Chem Res 3: 162. doi:10.4172/2329-6836.1000162

Ligustrumvulgare Under excess light and drought stress. New phytol 163: 547-561.

29. Lillo C, Lea US, Ruoff P (2008) Nutrient depletion as a key factor for manipulating gene expression and product formation in different branches of the flavonoid pathway. Plant Cell Environ 31: 587-601.

30. Leyva A, Jarillo JA, Salinas J, Martinez-Zapater JM (1995) Low Temperature induces the accumulation of phenylalanine ammonia-lyase and chalcone synthase mRNAs of Arabidopsis thaliana in a light-dependent manner. Plant Physiol 108: 39-46.

31. Løvdal T, Olsen KM, Slimestad R, Verheul M, Lillo C (2010) Synergetic effects of nitrogen depletion, temperature, and light on the content of phenolic compounds and gene expression in leaves of tomato. Phytochemistry 71: 605613.

32. Singh K, Kumar S, Rani A, Gulati A, Ahuja PS (2009) Phenylalanine ammonialyase (PAL) and cinnamate 4-hydroxylase $(\mathrm{C} 4 \mathrm{H})$ and catechins (flavan-3-ols) accumulation in tea. FunctIntegr Genomics 9: 125-134.

33. Yuan Y, Liu Y, Wu C, Chen S, Wang Z, et al. (2012) Water deficit affected flavonoid accumulation by regulating hormone metabolism in ScutellariabaicalensisGeorgi roots. PLoS One 7: e42946.

34. Dinelli G, Bonetti A, Elementi S, D’Antuono LF, Catizone P (2006) Biosynthesis of Polyphenol Phytoestrogens in Plants. In Yildiz F. (ed.), Phytoestrogens in Functional Foods. Boca Raton FL19-80. 